\title{
Two symposia worth reading: science, religion, and the history of mechanics
}

\author{
Luciano Boschiero ${ }^{1} \cdot$ K. Brad Wray ${ }^{2}$
}

Published online: 24 June 2019

(c) Springer Nature B.V. 2019

The relationship between science and religion is a source of countless books and perennial disagreement, in public fora as well as scholarly circles. These works and discussions have focused on historical detail—such as with regard to the infamous Galileo Affair-and a variety of philosophical, theological, and scientific approaches. In recent decades, the historical and philosophical discussion in academic circles has predominantly been on breaking down the old dichotomies of conflict and separation and replacing them with more complex accounts of an historical and intellectual interrelationship. However, Yves Gingras challenges this trend by questioning the extent to which dialogue can occur between the institutions and communities of scientists and theologians. In this issue of Metascience, a symposium based on Gingras' book contains some robust discussion that will undoubtedly trigger further debate. Indeed, as another indication that this debate is certain to continue, this issue of Metascience also contains standard-length reviews of more books on this topic, by John Hedley Brooke (on Alan Gross' The Scientific Sublime, 2018) and Mark Gardiner (on Andrew Steane's Science and Humanity, 2018).

We are also pleased to present another symposium to open this issue. In 2017, Alan Chalmers published a groundbreaking book on the history of mechanics and motion, the result of years of work. In the last two years, this subject matter, and Alan's approach to it, has been at the centre of several conferences and conversations about early modern science and experimental philosophy. As editors, it is our honour to bring to readers this symposium, featuring some excellent insights into the work of one of the most enduring and admired writers of the combined fields of history and philosophy of science.

To bring you these symposia and the excellent array of standard-length and essay reviews also in this issue, we are-as always-indebted to so many people that

Luciano Boschiero

1.boschiero@campion.edu.au

K. Brad Wray

kbwray@css.au.dk

1 Campion College, Sydney, Australia

2 Department of Mathematics, Centre for Science Studies, Aarhus University, Aarhus, Denmark 
deserve our thanks: reviewers who give up their time to contribute to the journal; book authors who of course provide the source for our content; publishers who are willing to send review copies around the world; the team at Springer who work so efficiently and professionally on the publication process; and our Assistant Editor who keeps us co-editors on task. We would like to single out Lucy Fleet, Senior Publishing Editor, at Springer for Philosophy and History of Science, who has overseen the publication of Metascience for several years. Sadly for us, Lucy has moved onto a different role at Springer. Stepping into her shoes is Ties Nijssen, who has also had a long association with the journal and its original parent institution, the Australasian Association for the History, Philosophy and Social Studies of Science. We would like to welcome Ties back to Metascience and thank Lucy for her work and support.

Publisher's Note Springer Nature remains neutral with regard to jurisdictional claims in published maps and institutional affiliations. 